${ }^{1}$ Dr. Mohammad Monsur Hallaz Assistant Professor of Urology Dept. of Surgery Northern International Medical College

${ }^{2}$ Prof. Dr BH Nazma Yasmeen Prof \& Head Dept. of Paediatrics Northern International Medical College

${ }^{3}$ Dr. Nadia Sultana Medical officer BSMMU

${ }^{4}$ Dr. Mahfuza Akter
Medical Officer
Dept. of gastroentology
DMCH
${ }^{5}$ Dr. Nurul Alam Basher
Assistant professor
Neuromedicine
Jamalpur Medical College
Hospital

Correspondence Dr. Mohammad Monsur Hallaz Assistant Professor Urology Department of Surgery Northern International Medical College, Dhaka

E-mail : mmhallaz@yahoo.com

\title{
Comparison of the efficacy of Solifenacin Succinate and Tolterodine for the treatment of overactive bladder syndrome
}

\author{
M M Hallaz ${ }^{1}$, B H N Yasmeen ${ }^{2}$, N Sultana ${ }^{3}$, M Akter ${ }^{4}$, N A Basher ${ }^{5}$
}

Abstract

Background: Overactive Bladder Syndrome $(\mathrm{OAB})$ is not an uncommon problem. Although exact incidence of this disease in our country is not known but a significant number of people suffering from this disease seek treatment at the Urology department of different hospitals. At present two common antimuscarinic drug Solifenacin Succinate and Tolterodine are available in our country for the treatment of OAB.

Objective : To compare the efficacy of Solifenacin Succinate and Tolterodine to treat OAB.

Methodology : This hospital based randomized control trial was conducted in the Department of Urology, Dhaka Medical College Hospital, Dhaka and a private hospital from January 2009 to December 2010 to compare the efficacy of two new generation antimuscarinics, Solifenacin succinate and Tolterodine at their recommended doses for the treatment of $O A B$.

Results : After 3 months of treatment it has clearly shown that Solifenacin is more effective in reducing OAB symptoms compared with extended release preparation of Tolterodine. This include statistically significant reduction in episodes of frequency, urgency, urge incontinence, nocturia and significant improvement of voided volume.

Key words : Overactive Bladder Syndrome (OAB), Solifenacin Succinate and Tolterodine.

Northern International Medical College Journal Vol. 8 No. 02 January 2017, Page 231-234

\section{Introduction}

$O A B$ is characterized by urgency, with or without urge incontinence, usually accompanied by increased micturition frequency and nocturia, in the absence of another identifiable metabolic or pathological process affecting the lower urinary tract. According to International Continence Society (ICS) OAB syndrome (or urge or urgency-frequency syndrome) is characterized by 'urgency, with or without urge incontinence, usually with frequency and nocturia. ${ }^{1}$ Reduction in voided volume and decreased bladder capacity is also included in this syndrome.

It is estimated that more than 17 million people in the USA and many millions worldwide are affected by $O A B{ }^{2} A$ recent study of 16000 adults from six European countries (France, Germany, UK, Sweden, Italy and Spain) concluded that more than 22 million adults in these countries may have $O A B{ }^{3}$ In a nationwide study in Japan the prevalence of $O A B$ was $12.4 \%$, or 8.1 million individuals. ${ }^{4}$ The prevalence of $O A B$ increases with age even though it is not a normal part of the ageing process.
However, $O A B$ is not a life-threatening condition but it significantly impairs the quality of life (QoL) of patients, and remains under-diagnosed and under-treated. ${ }^{2,3}$ The $O A B$ can have a deleterious effect on various domestic, occupational, sexual and psychosocial aspects of daily living, and has become a significant cause of increased healthcare costs and deteriorated social function. ${ }^{3,5,6}$

The most common cause of $O A B$ is detrusor overactivity, characterized by involuntary contraction of the detrusor muscle during bladder filling. ${ }^{1} \mathrm{~A}$ high frequency of voids (more than 8 voids/day) usually accompanies this disorder.

Pharmacological treatment of $O A B$ aims to reduce the symptoms of urgency and the frequencies of micturition and incontinent events. Because many patients will require life long treatment and to ensure good compliance, the ideal intervention should be needed that are easy to administer and have an acceptable safety profile. 
At present time a range of antimuscarinic agents are available and the efficacy of these drugs have been improved with the advent of extended release (ER) formulation e.g Tolterodine ER is the leaders in providing $O A B$ symptoms relief. Solifenacin succinate $(5 \mathrm{mg}$ and $10 \mathrm{mg}$ ) once daily is also a new generation antimuscarinic agent that has claimed to have good efficacy.

\section{Methods}

This randomized control trial was conducted at the in patient and outpatient (OPD) department of Urology, Dhaka Medical College Hospital and OPD of Department of Urology, Comfort Nursing Home from January 2009 to December 2010.

All the patients with overactive bladder (OAB) who were attended during the study period were included in this study after fulfilling the criteria.

\section{Inclusion (selection) criteria}

Patients who micturate more than 8 times in 24 hours, one or more than one incontinence episodes in 24 hours, one or more than one urgency in 24 hours, OBA confirmed by urodynamic study and newly diagnosed case of overactive bladder

\section{Exclusion criteria}

Patients who has stress incontinence, evidence of urinary tract infection, bladder stone, previous or current malignant disease of pelvic organs,Diabetes Mellitus and Renal failure.

Selected patient was evaluated by history, physical examination and relevant investigations. After collecting all reports, each patient was assessed to make sure that they were within selection criteria. After proper explanation of all aspects of the study written consent was taken from the patient. In this study 40 patient of OAB were selected who were fulfilled the inclusion criteria and divided into two groups by simple lottery method. Odd numbers for experimental group who received Solifenacin $10 \mathrm{mg}$ once daily and even numbers for control group who received Tolterodine ER 4mg once daily.

Before commencement of the study, patients was requested to complete micturition diary which include number of episodes of urinary frequency, urgency, nocturia, urge incontinence, the voided volume. Urodynamic studies were done and pressure during filling and voiding phase was recorded.

Patient was send home with treatment and advised for follow-up at a fixed date after three months and reevaluated. Urodynamic study was also repeat in this visit. All data (baseline and after 3 months of treatment) were collected from history, findings of clinical examination, results of investigations, mucturation diary and Urodynamic tracing. Then the results were expressed as frequency, percentage, mean $\pm \mathrm{SD}$. The comparison of continuous variables between two groups was done by student's't' test. The comparison of the categorical variables was done by chi-square test. $p$ value $<0.05$ was considered as significant.

\section{Results}

A total of 40 patients with $O A B$ were selected for the study according to the selection criteria. Twenty of them were given Solifenacin10 mg and another 20 were given Tolterodine $4 \mathrm{mg}$ ER for 3 months.

Among them $50 \%$ of the patients were in $21-40$ years of age followed by $27.5 \%$ in $41-60$ years group, $12.5 \%$ patients were in group 'up to 20 years'. Three (7.5\%) belong to group $61-80$ years and only $1(2.5 \%)$ patient was in to 'more than 80 years' age group. (Table-I)

\begin{tabular}{|c|c|c|c|}
\hline Age group (years) & Frequency & Percentage (\%) & $\begin{array}{c}\text { Mean } \pm S D(y r s) \\
\text { (Range) }\end{array}$ \\
\hline $\begin{array}{l}\text { Up to } 20 \text { years } \\
\text { (8-86 years) }\end{array}$ & 5 & 12.5 & $36.1 \pm 17.1$ \\
\hline $21-40$ years & 20 & 50.0 & \\
\hline $41-60$ years & 11 & 27.5 & \\
\hline $61-80$ years & 3 & 7.5 & \\
\hline More than 80 years & 1 & 2.5 & \\
\hline
\end{tabular}

The experimental group had 11(52.4\%) male and 9(47.6\%) female and the control group had $10(50 \%)$ male and $10(50 \%)$ female. The difference in gender between two groups was not statistically significant $(p=0.752)$. (Table-II) Also the comparison of mean age between experimental and control group was not statistically significant $(p=0.199)$. (Table-III)

Table-II: Distribution of patients by gender

\begin{tabular}{lccc} 
Group & \multicolumn{2}{c}{ Sex } & $\boldsymbol{p}$ value \\
& Male & Female & .752 \\
Experimental $(n=20)$ & $11(52.4 \%)$ & $9(47.6 \%)$ & \\
Control $(n=20)$ & $10(50 \%)$ & $10(50 \%)$ &
\end{tabular}

Table-III : Comparison of mean age between experimental and control group (t test)

$\begin{array}{llc}\text { Group } & \text { Mean } \pm \text { SD } & \boldsymbol{p} \text { value } \\ \text { Experimental }(n=20) & 39.6 \pm 19.1 & 0.199 \\ \text { Control } \quad(n=20) & 32.6 \pm 14.4 & \end{array}$

The change in mean number of urinary episodes/24 hour, urgency episodes/24 hour, urge incontinence (episodes/24 hours), nocturia (episodes/night), voided volume ( $\mathrm{ml} / 24$ hour) in experimental group treated with Solifenacin; compared with the change in the control group treated by Tolterodine group.

The urinary frequency of Solifenacin group was at baseline and 3 months after treatment were $17.10 \pm 6.31$ and $10.00 \pm 2.47$ episodes/24 hours respectively. The reduction in urinary frequency was $38.82 \pm 9.3$. The urinary frequency of tolterodine group at baseline and 3 months after treatment were $15.90 \pm 4.98$ and $11.6 \pm 3.66$ episodes/24 hours respectively. The reduction in urinary frequency was $25.85 \pm 10.75$. The reduction 
of urinary frequency of Solifenacin group was significantly higher than Tolterodine group $(p<.001)$. (Table-IV)

Three months after treatment in the Solifenacin group mean $( \pm S D)$ reduction in urinary urgency was $69.7( \pm 15.66)$ and in Tolterodine group was 47.38 ( \pm 12.03$)$. The reduction of urinary urgency of Solifenacin group was significantly higher than Tolterodine group $(p<.001)$ (Table-IV)

The mean $( \pm S D)$ reduction of urinary urge incontinenceof Solifenacin group after 3 months of treatment was 90.56 $( \pm 14.09)$ but in Tolterodine group mean $( \pm S D)$ reduction was $53.57( \pm 24.61)$.The reduction of urinary incontinence was significantly higher in Solifenacin group than tolterodine group $(p<.001)$. (Table-IV)

In Solifenac in group mean ( $\pm S D$ ) reduction of frequency of nocturia from base was $72.75( \pm 21.02)$ after 3 months of treatment and in Tolterodine group was $47.08( \pm 12.17)$. The reduction of frequency of nocturia of Solifenacin group was also significantly higher than Tolterodine group $(p<.001)$ (Table-IV)

The increment of voided volume of Solifenacin group after treatment was $47.25( \pm 48.3)$ and in Tolterodine group was $15.92( \pm 18.77)$. The increment in voided volume of Solifenacin group was significantly higher than Tolterodine group $(p<.01)$.

Table-IV : the change in the mean number of urinary frequency, Characteristics urgency, urge incontinence, nocturia and voided volume

\begin{tabular}{lcc} 
& $(\mathbf{n}=\mathbf{2 0})$ & $\mathbf{( n = 2 0 )}$ \\
Urinary frequency (episodes/24 hours) & & \\
Baseline (mean \pm SD) & $17.10 \pm 6.31$ & $15.90 \pm 4.98$ \\
After tretment & $10.00 \pm 2.47$ & $11.65 \pm 3.66$ \\
Change from baseline & $7.1 \pm 4.17$ & $4.25 \pm 2.61$ \\
Estimated difference from control group & 2.85 & \\
Percent change from baseline & $38.82 \pm 9.32$ & $25.85 \pm 10.75$ \\
$95 \%$ CI & $6.527,19.412$ & \\
$p$ & $<.001$ & \\
Urgency (episodes/24 hours), N & & \\
Baseline (mean \pm SD) & $5.60 \pm 2.16$ & $4.85 \pm 2.03$ \\
After tretment & $1.70 \pm .80$ & $2.55 \pm 1.23$ \\
Change from baseline & $3.90 \pm 1.68$ & $2.30 \pm 1.17$ \\
Estimated difference from control group & 1.6 & \\
Percent change from baseline & $69.70 \pm 15.66$ & $47.38 \pm 12.03$ \\
(95\% CI) & $13.381,31.261$ & \\
p & $<.001$ & \\
Urge incontinence (episodes/24 hours), N & & \\
Baseline (mean $\pm S D)$ & $2.45 \pm 1.61$ & $1.50 \pm 1.19$ \\
After tretment & $0.35 \pm .59$ & $0.75 \pm .72$ \\
Change from baseline & $2.10 \pm 1.21$ & $.75 \pm .64$ \\
Estimated difference from control group & 1.35 & \\
Percent change from baseline & $90.56 \pm 14.09$ & $53.57 \pm 24.61$ \\
(95\% CI) & $22.888,51.080$ & \\
$p$ & $<.001$ & \\
\hline
\end{tabular}

Nocturia (episodes/night)

$\begin{array}{lcc}\text { Baseline (mean } \pm \text { SD) } & 3.45 \pm 1.39 & 3.40 \pm 1.23 \\ \text { After tretment } & 1.05 \pm .83 & 1.80 \pm .77 \\ \text { Change from baseline } & 2.40 \pm .94 & 1.60 \pm .75 \\ \text { Estimated difference from control group } & 0.80 & \\ \text { Percent change from baseline } & 72.75 \pm 21.02 & 47.08 \pm 12.17 \\ (95 \% \mathrm{CI}) & 14.670,36.662 & \\ p & <.001 & \end{array}$

Voided volume ( $\mathrm{ml} / 24$ hour)

$\begin{array}{lcc}\text { Baseline }(\text { mean } \pm \text { SD) } & 191.50 \pm 121.73 & 213.50 \pm 111.2 \\ \text { After tretment } & 240.15 \pm 103.5 & 230.75 \pm 104.6 \\ \text { Change from baseline } & -48.65 \pm 24.86 & -17.25 \pm 8.83 \\ \text { Estimated difference from control group } & -31.4 & \\ \text { Percent change from baseline } & -47.25 \pm 48.30 & -15.92 \pm 18.77 \\ 95 \% \text { CI } & -54.781,-7.866 & \\ p & .005 & \end{array}$

The mean $( \pm S D)$ reduction in pressure of filling phase of Solifenacin group with 3 months treatment was 40.35( \pm 9.11$)$ and in Tolterodine group mean $( \pm S D)$ reduction phase was $25.05( \pm 9.14)$. The reduction in pressure of filling phase of Solifenacin group was significantly. The reduction in pressure of voiding phase in Solifenacin group was significantly more than Tolterodine group $(p<.001)$.

Table-VI: The change in mean filling phase pressure and voiding phase pressure Characteristics

Filling phase pressure Baseline (mean \pm SD)

Experimental group Control group $(n=20)$ $(n=20)$

$\begin{array}{lcc}\text { Baseline }(\text { mean } \pm \text { SD) } & 46.75 \pm 22.09 & \\ & 37.65 \pm 17.57 & \\ \text { After tretment } & 28.3 \pm 14.32 & 29.30 \pm 15.93 \\ & & \\ \text { Change from baseline } & 18.45 \pm 9.15 & 8.35 \pm 2.68 \\ \text { Estimated difference from control group } & 10.10 & \\ \text { Percent change from baseline } & 40.35 \pm 9.11 & 25.05 \pm 9.15 \\ 95 \% \text { CI } & 9.452,21.142 & \\ p & <.001 & \\ \text { Voiding phase pressure } & & \\ \text { Baseline (mean } \pm \text { SD) } & 78.05 \pm 18.51 & 68.10 \pm 15.25 \\ \text { After tretment } & 60.15 \pm 12.67 & \\ & 59.00 \pm 12.46 & \\ \text { Change from baseline } & 17.90 \pm 8.05 & 9.10 \pm 3.10 \\ \text { Estimated difference from control group } & 8.80 & \\ \text { Percent change from baseline } & 22.39 \pm 6.03 & 13.07 \pm 3.84 \\ 95 \% \text { CI } & 6.080,12.554 & \\ p & <.001 & \end{array}$

\section{Discussions}

Although the exact incidence of patient suffering from $O A B$ in Bangladeshis not known, we have to deal a good number patient in our day to day practice in the department of Urology. As $O A B$ is a bothersome condition and it significantly reduces the quality of life of a person, establishing effective treatment for management of $O A B$ is an important challenge. Recently 
launched antimuscarinic agent Solifenacin has been claimed more selective ( $M_{3}$ receptor) and effective in the treatment of OAB. Another antimuscarinic agent Tolterodine is neither bladder nor muscarinic receptor subtype selective but it is cheaper.

This hospital based prospective study was done to evaluate the efficacy of these two new generation antimuscarinics with their recommended doses in treating OAB.

Forty $O A B$ patients divided into two groups, experimental group (Solifenacin 10mg) and controll group (Tolterodine 4mg ER).

In this study in Solifenacin group- the reduction of urinary frequency was $38.82 \pm 9.32$ and in Tolterodine was $25.85 \pm 10.75$. In Solifenacin group mean $( \pm S D)$ reduction of frequency of nocturia from base to 3 months after treatment was $72.75( \pm 21.02)$, and was $47.08( \pm 12.17)$ in Tolterodine group The improvement of frequency and nocturia with Solifenacin is statistically significant $(p<0.001)$. The result reflect superiority of Solifenacin over Tolterodine in reducing frequency and nocturia which is similar to result of studies conducted by Chapple et al. ${ }^{8,9}$

In the study of Chapple et al. neither Solifenacin nor Tolterodine treated patients experienced a significant reduction in the number of urgency or incontinence episodes. ${ }^{8}$

The mean number of incontinence decrease in episodes with Tolterodine $(p=0.1122)$ but a significant decrease in patients treated with Solifenacin $(p=0.0038)$ was found in this stuey.

Solifenacin group showed statistically significant improvements in urgency $(p=0.035)$ and urge incontinence $(p=0.001)$ after treatment and which was consistent with the study of Chapple et al. ${ }^{9}$ In our study the result reflected that mean reduction of the urgency and urge incontinence was also have been reduced in greater numbers with both the drugs. These reduction of symptoms by Solifenacin is highly significant than Tolterodine.

The mean voided volume per void was increased $43.2 \mathrm{ml}$ (35\%) from the baseline in case of Solifenacin and it was $14.7 \mathrm{ml}(14 \%)$ with Tolterodine in the study of Chapple et al. ${ }^{8}$ Voided volume per micturition in case of Tolterodine was not significant but it was significant in patients treated with Solifenacin in comparison to placebo.

In another study Chapple et al. found that after treatment with Solifenacin mean voided volume was increased $39.2 \mathrm{ml}(29 \%)$ but with Tolterodine increment was $24.4 \mathrm{ml}(20 \%) .{ }^{8}$ In our study the mean voided volume per micturition was also significantly higher with Solifenacin compared with Tolterodine $(p<0.001)$. In this study, mean increment in voided volume of Solifenacin group and Tolterodine group were $48.65 \pm 24.86 \mathrm{ml}$ and $17.25 \pm 8.83 \mathrm{ml}$ respectively. The increment in voided volume of Solifenacin group was significantly more than Tolterodine group $(p=0.005)$.
In our study we found that the reduction in pressure of filling phase and voiding phase of Solifenacin group was significantly higher than Tolterodine group $(p<.001)$.

There is no comparative study available regarding filling and voiding pressure change after treatment with these two drugs. But the study result of Tanaka et al. is not consistent with the result of our study. ${ }^{10}$

\section{Conclusion}

The present study conclude that in the management of overactive bladder patient antimuscarinic drug Solifenacin succinate is more effective than Tolterodine.

\section{References}

1. Abrams $P$, Cardozo L ,Fall M , 'The standardization of terminology of lower urinary tract function: report from the standardization sub-committee of the International Continence Society',2002, NeurourolUrodyn, vol. 21, pp.167 178.

2. Rovner ES \&Wein AJ, ' Incidence and prevalence of overactive bladder',2002 CurrUrol Rep, vol. 3, pp. $434-438$.

3. Milsom I, Stewart W\&Thüroff], 'The prevalence of overactive bladder',2000Am J Manag Care, vol.6, pp.565 - 573.

4. Homma $Y$, Yamaguchi $O$ \& Hayashi $K$ 'An epidemiological survey of overactive bladder symptoms in Japan'.2005,BJU International, vol.96, pp. 17.

5. Wein AJ \&Rovner ES, 'The overactive bladder: an overview for primary care health providers',1999,Int J Fertile Womens Medical,vol. 44, pp. $56-66$.

6. Abrams P, Kelleher CJ, Kerr LA \&Rogers RG 'Overactive bladder significantly affects quality of life',2000,Am J Manag Care, vol.6, pp. $580-90$

7. Chapple CR, AranoP , Bosch JLHR, De Ridder D, Kramer AEJL,Ridder AM 'Solifenacin appears effective and well tolerated in patients with symptomatic idiopathic detrusor overactivity in a placebo- and tolterodinecontrolled phase 2 dose-finding study',2004,B.J.U International, vol. 93,pp.71-77.

8. Chapple CR, Rechberger T, Al-Shukri S, Meffan P, EveraertK ,Huang M 'Randomized, double-blind placebo- and tolterodine-controlled trial of the once-daily antimuscarinic agent solifenacin in patients with symptomatic overactive bladder',2004,B.J.U International,vol.93,no.3, pp.303-310.

9. Chapple CR, Martinez-Garcia R, Selvaggi L, Toozs-Hobson P ,Warnack W, Drogendijk $T$ et al.'A Comparison of the efficacy and tolerability of Solifenacin Succinate and extended release Tolterodine at treating Overactive Bladder syndrome: Results of the STAR trial',2005,EurUrol, vol. 48, pp. 464-470.

10. Tanaka $Y$, MasumoriN ,Tsukamoto T, 'Clinical Investigation: Urodynamic effects of solifenacin in untreated female patients with symptomatic overactive bladder',2010,International journal of Urology, vol.17, no.9, pp.796-800. 